\title{
Visualized Musical Narrative in The Great Gatsby
}

\author{
Xin Lin \\ School of Liberal Arts, Jinan University, 601 Huangpu Ave, Guangzhou, China \\ E-mail: milanda0430@163.com
}

Keywords: F. S. Fitzgerald, The Great Gatsby, Narrative, Jazz Music.

\begin{abstract}
As one of the most famous modern American novels, The Great Gatsby is a symbolic master work describing the urban life during “Jazz Age” (1919-1929). Music, especially Jazz music, played a dominate role in social and entertainment activities among the young generation by influencing their attitude and reflecting contemporary viewpoints of the world they lived in. The author, F. S. Fitzgerald, portrayed the abundant of scenes of music in the novel by using visual and visible ways. The music itself was no longer the center of storytelling on condition that it had been described as the atmosphere and reflecting the strong powerful effect jazz music produced. By describing the visual music scenes in The Great Gatsby, the author exposed the luxury lifestyles and restless mind states of people during Jazz Age. Music scene is the object of description and background of time in the novel, which forms Fitzgerald's unique modern narrative style.
\end{abstract}

\section{Introduction}

Fitzgerald tried to explain the cultural significance of jazz age vividly in Echoes of The Jazz Age: "It was an age of miracles, it was an age of art, it was an age of excess, and it was an age of satire" $[1]^{131}$. "By 1923 their elders, tired of watching the carnival with ill-concealed envy, had discovered that young liquor will take the place of young blood, and with a whoop the orgy began. The younger generation was starred no longer" [2] ${ }^{132}$. According to this famous essay written by Fitzgerald, spokesman of Jazz Age-1920s is also known as Jazz Age. Simultaneously, in The Great Gatsby, Fitzgerald mainly portrayed images and psychological states of the young generation in 1920s. It seems like that people over forty don't exist in the works of Fitzgerald. The fashionable taste and principles of value of young people dominated mainstream of public opinion, which was having fun and enjoying every interesting thing as much as possible. As a result, the whole American society in 1920s was caught in unnecessary expenses and endless pleasure and it was reflected in The Great Gatsby. Because of accurately exposing the spirit of Jazz age, Henry Dan Piper praises "Fitzgerald's work (The Great Gatsby) is even greater than contemporary chronicle in the aspect of describing history" [3] ${ }^{1}$. Lionel Trilling also makes beautiful comments on The Great Gatsby and Fitzgerald and considers that "His literal accomplishment can compare with Goethe's." $[4]^{202}$ In The Great Gatsby, it can be seen that entertainment, especially Jazz music, automatically played a leading role on people's daily life. The narrative methods of describing music is to visualize auditory effect in order to demonstrate in context.

\section{The entertainment and party culture in Jazz Age}

The popularization of entertainment during “Jazz Age” didn't mean the comprehensive enhancement of the living standards of the American general public in the early $20^{\text {th }}$ century. The most beautiful stories created by Fitzgerald all happened in cities, and mainly in New York, where characters were mostly born in upper class, well-educated and bound up in social activities. Fitzgerald's "Jazz Age" belonged only to cities, while the massive poorer class were forgotten and their son, Gatsby, was ashamed of all these and mentally dissevered his affection with his parents, believing in himself to be "the son of God". Gatsby is a mixture of the Christian religious spirit and the desire for the noble life. Regarding wealth and status as his God, Gatsby was determined to pursue "a vast, vulgar, and meretricious beauty[5] ${ }^{129}$ ". While Gatsby was spending billions to feast 
his guests in West Egg, he's actually telling everyone that finally he managed to become part of the "Jazz Age".

Party culture in the 1920s was closer to the concept of parties today: playing and entertaining. When Nick Carraway came to Gatsby's party for the first time, people from nearly half of the city all showed up, and Nick thought of himself to be the only one who had an invitation card. Because the party was not held for marriage, guests even wouldn't indicate their marital states, and from the "Jazz Age" up till now, the purpose of a party had become irresponsible gossiping and looking for one-night stands.

From the 1920s to the 1930s, the scale of a jazz band kept expanding, with more and more different kinds of musical instruments added. When it came to the "Swing Music" massive jazz band age in the 1930s, a jazz band had evolved to a scale that more than ten people were up on the stage, the diversity and richness of the instruments brought about chords effect and flexible rhythms with a rich variety of instrumental parts, which made it possible for the players to get rid of the main melody and make improvisations during the performance. It is very difficult to present the auditory effect by words, and the changeful melody of jazz even increase the difficulty to present the musical charm of jazz in literary works.

\section{Scenes description of Jazz music in The Great Gatsby}

In The Great Gatsby, the author paid lots of attention on the parties at Gatsby's house. But the focus of the narrative by Fitzgerald was not the jazz music itself, or in some other words, the meaning of the existence of jazz music at the party was beyond the simple melody: "By seven o'clock the orchestra has arrived, no thin five-piece affair, but a whole pitiful of oboes and trombones and saxophones and viols and cornets and piccolos, and low and high drums" [6] ${ }^{49}$.The Great Gatsby was written during the years from 1923 to 1925, and at the beginning of the 1920s, jazz bands always played in underground bars and casinos, which were usually tiny spaces, therefore the scales of the bands were not big, they were mainly small bands including 3 to 5 players. It's not until in the 1930s, after ten years' evolving and flourishing since the 1920s, did jazz bands came out to large theatres, large swing music jazz band being popular and the number of players in a band adding up to more than 10. After World War I (1914-1918), the whole Europe fell into a wasteland of spirit and culture, just as Spengler described in The Decline of the West. But the U.S. not only survived, but also got a great deal of fortune from the war, which immersed the whole American land in a scene of prosperity and happiness. Fitzgerald described the grand party at Gatsby's from the angle of Nick, and in his constantly changing aspects, we could see the importance of a jazz band in a party according to its appearance. People preferred to dance somewhere near the band, and descriptions of the band just highlighted the joyful atmosphere. He said nothing about what kind of melody was the band playing, and Nick caught sight of quite a lot of details at the party and descriptions of the behaviors, conversations and expressions of the guests were made, but only the audio description of the most important jazz music at the party was missing.

At the climax of the party, the conductor announced that they were about to play "Vladimir

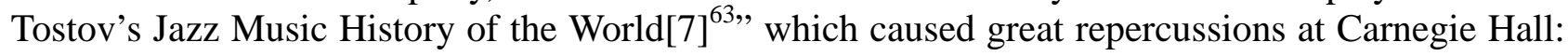
“The nature of Mr. Tolstoy's composition eluded me, because just as it began my eyes fell on Gatsby, standing alone on the marble steps and looking from one group to another with approving eyes.......when the Jazz History of the World was over, girls were putting their hands on men's shoulders in a puppyish, convivial, girls were swooping backward playfully in to men's arms even into groups, knowing that someone would arrest their falls-but no one swooned backward on Gatsby, and no french bob touched Gatsby's shoulder, and no singing quartets were formed with Gatsby's head for one link[8] $]^{64 "}$.

Nobody's enjoying the band seriously at Gatsby's party, and the band was just acting as the backdrop of people's entertainment. Actually, even nobody cared about who the host was. In Tender Is the Night mentioned above, Fitzgerald said people took part in social activities out of their loneliness, while in The Great Gatsby, Parties held by Gatsby were quite utilitarian. Gatsby, with 
his sudden wealth, held grand parties extravagantly to show the public his economic power. However, he failed to gain the respect and gratitude of the public. On the contrary, it brought about doubts from the public against his huge property of unknown origin. One purpose of the descriptions of the party in the novel was to reveal the profligacy of the propertied class during "Jazz Age". The whole American society were deeply addicted to the vanity within conspicuous consumption to present their self-identities and to look for acknowledgement. Gatsby was unknown at the party. Luxurious dancing and partying life didn't bring friends to Gatsby, and he stood alone at the party, being the only one who couldn't get along with the group. Eventually, Gatsby's wealth didn't win him Daisy's love, social respect neither. During the "Jazz Age”, in which consumer culture played a leading role, the behavior of wasting and luxury could only satisfy people's momentary physical pleasure. And Gatsby's party offered a free place for countless strangers to entertain, with a goal to spread his fame, and actually, he did it-we could tell from the conversation between Jordan Baker and Nick that Gatsby's party was quite famous in New York. The relationship between Gatsby and his guests was some kind of consumption one, and Gatsby provided free "services". The guests all disappeared after Gatsby's death, and it was not merely a complaint against the cruelty and indifference of the consumer society. What's more, it's not difficult to tell from Gatsby's party that there's no special reason for his guests to feel sorry about him, because Gatsby held the party with a commercial aim of exchanging, never expecting to set up any emotional connection with his guests. Therefore, as soon as he renewed the relationship between him and Daisy, thus achieving his target, there were no longer any parties at Gatsby's.

\section{The narrative implication of jazz music in The Great Gatsby}

In the novel, the nature and function of musical performance to show off the host's economic power of the large jazz band at the party plays a more important role than its being a professional music band. Nick said he didn't pay much attention to Tolstoy's music, and as a matter of fact, everybody at the party all focused on entertaining themselves, and nobody really cared about what was the band playing or how the band was playing. All they wanted from the band was to bring them the proper atmosphere to dance. Visibly, all kinds of entertainment during the "Jazz Age" were with the same goal to offer visual effect, and the reason why large jazz band would become a trend of the jazz music was that the audiences were not only chasing for the enjoyment of ear, but also in need of the music sense and passion through their body movements and facial expressions. And when a large jazz band was playing, the musicians were divided into different parts to play out the various and interesting polyphony, including interactions between players and between players and audiences, the conductor would also sign for and guide the audiences' emotions by the same time he led the band. At Gatsby's party, it was the ostentation and extravagance and performance rather than the music itself that was the object of Nick's narrative, in order to show how luxurious and hilarious the party was: Whenever there was a pause in the song she filled it with gasping, broken sobs, and then took up the lyric again in a quavering soprano. The tears coursed down her cheeks-not freely, however, for when they came into contact with her heavily beaded eyelashes they assumed an inky color, and pursued the rest of their way in slow black rivulets. A humorous suggestion was made that she sing the notes on her face. Whereupon she threw up her hands, sank into a chair, and went off into a deep vinous sleep[9] $]^{65}$.

Jazz music used to be the most popular music style during "Jazz Age”, which was named after a form of music by Fitzgerald. During this age, great changes took place in social attitude towards music. Music had become part of popular entertainment, and the public had more request against public music art, requiring not only sensual pleasure, but other forms like visual one as well. Up till now, it has become more and more important to perform and act in playing popular music, the public wanting to see magnificent stage design as well as the singers dancing and singing. In the description given by Fitzgerald about music live, he had already foreseen the trend of performing and visualizing of music.

The music involved in Fitzgerald's novel was typical kind of popular music during 1920s, such as jazz, musical and folk, part of which could be found on the Internet at present. And for 
contemporary readers who are nearly 100 years later than "Jazz Age", as time went by, the then popular music has already entered the classical music hall, classified in the category of classical music. Though jazz is still quite popular in today's popular music as a kind of music rhythm element, popular jazz nowadays is more mixed up with rock, electron and other music styles, totally different from that during the 1920s in rhythm and performing style. The film LA LA Land, the big heat during the Oscar period this year, pointedly reveals the contrast between the decline of traditional jazz and the boom of popular jazz by telling the story of a traditional jazz musician's hard music career. If contemporary readers, especially those who were born after 2000, ever try to go back to "Jazz Age" to witness the entertaining atmosphere simply by listening to the audios from 100 years ago, they will probably get disappointed by the "fusty", "old-fashioned" and "boring" kind of feel. It has always been pretty difficult to show the charm of the music melodies in literary works, since words can only make indirect narrations while sounds are firstly hearing feelings.

\section{The significance of visualization of music scenes}

Different from visualized writing, which is based on the visuality that words and images have in common, hearing and reading are totally different kinds of sensory feelings, the former using ears while the latter using eyes. Detailed on to the selecting of music in novels, except for some classic ones which stand over time or which are beyond the barrier of language and culture, the regional and currency characters of music, especially popular music, mean that only those of the same period, the same language and the same cultural backgrounds with the author would be able to understand the cultural meanings and writing backgrounds behind the music. As a kind of hearing art, music is quite limited in the creation practice of literature.

However, the possibility of making words audible was realized by Fitzgerald in "Jazz Age". With the rapid development of science and technology in the $20^{\text {th }}$ century, phonograph, radio and record took their place one by one and quickly got popularized, realizing the preservation and transmission of music; while in the $19^{\text {th }}$ century, the range of the audience of music was quite limited, the only way to transmit music was to play alive. From the technology aspect, real public popular music didn't come into being until music was copied and saved and went into market as a commodity. The popular music during "Jazz Age" seized the chance and became the first of all the cultural trends which had influences on all classes, regions, races and ages in American popular music history and even public culture history, and New York, where Fitzgerald lived and came up with his inspirations, not only was the center of jazz music during that time, but also provided all-year-round operas and musicals on Broadway on the Fifth Avenue, and buskers could be seen everywhere in restaurants, bars, hotels and on streets.

Compared to the general public in the $19^{\text {th }}$ century, to American people in 1920 s, music was just a common entertainment of their daily life, and popular music during "Jazz Age" had unprecedented mass acceptance and spreading breadth. What's most important, unlike theatres during the $19^{\text {th }}$ century which were only open to upper and well-educated class, jazz bars and Broadway theatres were open to all classes just as they do today, which made music playing and performing not mysterious any more, and during "Jazz Age", the acceptance and understanding of the public towards music reached a considerable height.

Not only the forms of spreading and performing of music during the "Jazz Age" had a tendency of being democratized and commercialized, but also the rhythms and lyrics got more close to public aesthetic taste. The form of improvisation, strong rhythms suitable for dancing and simple lyrics that were easy to keep in mind, all these characteristics of jazz music lowered the standards of a professional musician as well as the training costs. Meanwhile, not only the highly recreational music form of jazz appealed to young people's daily social and entertaining activities, but also the artistry of itself had become a way to express their personalities for young people.

\section{Conclusion}

The music scene in The Great Gatsby indicates that people had much more expectation on the 
performing form of music than on music itself during "Jazz Age", and the rhythm of music as a purely auditory feel was difficult to express by words, while the performance of music and the narrative art of lyrics could completely be described through words. There are lots of contents that reflect the temporal popular music in Fitzgerald's works and Fitzgerald is one of the most excellent sensory descriptors among the American writers during the first half of the $20^{\text {th }}$ century. In order to reproduce the extravagant and dissipated atmosphere of "Jazz Age" in his work, descriptions and display of music are essential. Music not only acts as the object of description and background of time in the work, but also builds up a visible and audible effect, which forms Fitzgerald's unique modern narrative mode from the aspect of narrating.

\section{References}

[1][2] F. S. Fitzgerald, James L. W. West. III, ed . My Lost Cites: Personal essays, 1920-1940[M]. New York: Cambridge University Press, 2013,131-132.

[3] Piper H. D. "Fitzgerald: The Great Gatsby: The Novel, The Critics, The background”[M]. New York: Scribner’s, 1970,1.

[4] Kazin A, ed. Fitzgerald: The man and his work[M]. New York: Collier Books, 1962,202.

[5][6][7][8][9] F.S.Fitzgerald . The Great Gatsby[M]. Beijing: China Space Press, 2011,129, $49,63,64,65$. 